\title{
ARTí́CULO \\ Respuesta de la abundancia y estructura de tamaño del bacterioplancton a diferentes condiciones oceanográficas en bahía Chipana $\left(21^{\circ} 20 ’ S\right)$
}

Response of the abundance and size structure of bacterioplankton to different oceanographic conditions in Chipana Bay $\left(21^{\circ} 20^{\prime} \mathrm{S}\right)$

\author{
Edgardo Santander ${ }^{1,2 *}$, Enzo Rojas ${ }^{3,4}$, Rubén Moraga ${ }^{1}$ y Paula Salinas ${ }^{1,4}$ \\ ${ }^{1}$ Unidad de Ecología y Diversidad Procariótica, Facultad de Recursos Naturales, Universidad Arturo Prat, Casilla 121, Iquique, Chile. \\ *esantan@gmail.com \\ ${ }^{2}$ Programa de Magister en Ciencias Aplicadas mención Biología Pesquera, Universidad Arturo Prat, Avenida Arturo Prat 2120, Iquique, \\ Chile \\ ${ }^{3}$ Corporación de Estudios y Desarrollo Norte Grande, Baquedano 958, of.1, Iquique, Chile \\ ${ }^{4}$ Programa de Magister en Gestión y Derecho Ambiental, Universidad Arturo Prat, Avenida Arturo Prat 2120, Iquique, Chile
}

\begin{abstract}
The relationship between bacterioplankton and oceanographic conditions of an upwelling area of northern Chile was analyzed, during two contrasting seasons, emphasizing an approach based in the abundance and size structure. The study area was Chipana Bay $\left(21^{\circ} 20^{\prime} \mathrm{S}\right)$, and analyzed the summers of 2004-2006 and winters of 2005-2007. The temperature, salinity and oxygen were recorded with a CTD and the bacterioplankton and chlorophyll-a samples were obtained at standards depths. The variability of the physical structure of the water column was associated with upwelling, under the influence of the oxygen minimum zone and El Niño-La Niña events. The higher abundance of bacterioplankton was observed in December 2004 and July $2005,\left(1.07 \times 10^{9}-5.12 \times 10^{9}\right.$ cell L$^{-1}$ and $1.44 \times 10^{9}$ cell $\mathrm{L}^{-1}$, respectively), associated with coastal margin and surface water away from the coast. For 2006 and 2007, a lower abundance was detected in the coastal margin and in the surface layer of the offshore stations, the values fluctuated between $6.77 \times 10^{7}-3.67 \times 10^{9} \mathrm{cells} \mathrm{L}^{-1}$, respectively. The use of generalized additive models determined that the best predictors were salinity, dissolved oxygen and the total chlorophyll. The higher cell volumes associated with low abundance, being the dominant structure size 0.4-0.8 and 0.8-1.2 $\mu \mathrm{m}$ in length. This study suggests that the abundance and cellular size of bacterioplankton undergo temporal variations that are related to physical factors, mainly salinity and stability of the water column. The observed transition between El Niño and La Niña causes changes in the water column associated with a deepening of the thermocline, which expands and contracts the $\mathrm{OMZ}$, which could eventually affect the productive capacity of the bacterioplankton.
\end{abstract}

Key words: Coastal upwelling, bacterioplankton, abundance, volume, size structure, environmental influence

Resumen.- Se analizó la relación entre el bacterioplancton y las condiciones oceanográficas en un área de surgencia en el norte de Chile, mediante aproximación basada en las abundancias y tamaños celulares. El área de estudio fue bahía Chipana ( $21^{\circ} 20^{\prime} \mathrm{S}$ ), se analizaron los veranos del 2004-2006 y los inviernos 2005-2007. La temperatura, salinidad y oxígeno se registraron mediante un CTD, las muestras de bacterioplancton y clorofila-a fueron obtenidas a profundidades estándares. La variabilidad de la estructura física de la columna de agua se asoció a eventos de surgencia, bajo la influencia de la zona de mínimos de oxígeno y eventos EI Niño-La Niña. La mayor abundancia del bacterioplancton se observó en diciembre 2004 y julio 2005 , asociadas al margen costero $\left(1,07 \times 10^{9}-5,12 \times 10^{9}\right.$ cél L $^{-1}$ y $1,44 \times 10^{9}$ cél L $^{-1}$, respectivamente). Para el 2006 y 2007 , se detectó una menor abundancia en el margen costero y en la capa superficial de las estaciones más alejadas de la costa, los valores fluctuaron entre $6,77 \times 10^{7}$ -

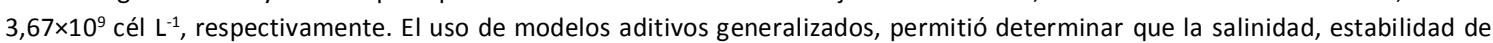
la columna de agua y biomasa del fitoplancton tuvieron un efecto significativo sobre la abundancia procariota. Los mayores volúmenes celulares se asociaron a las menores abundancias, siendo la estructura de tamaño dominante $0,4-0,8$ y 0,8-1,2 $\mu$ m de longitud. Este estudio sugiere que la abundancia y el tamaño celular del bacterioplancton sufren variaciones temporales que se relacionan a factores físicos, principalmente la salinidad y estabilidad de la columna de agua. La transición observada entre eventos El Niño-La Niña genera cambios en la columna de agua asociados a una profundización de la termoclina, que expande y contrae la OMZ, que finalmente podrían afectar la capacidad productiva del bacterioplancton.

Palabras clave: Bacterioplancton, abundancia, volumen, estructura de tamaño, surgencia costera, influencia ambiental 


\section{INTRODUCCIÓN}

El estudio de la oceanografía microbiana, en particular de la dinámica de las comunidades picoplanctónicas ha revelado que esta fracción es un importante componente del plancton marino (Azam et al. 1983, Delong \& Karl 2005). La abundancia de estos es modulada al igual que los demás componentes del plancton, por factores abióticos y bióticos, que regulan su abundancia, tamaño, biomasa, distribución y adaptación (Ducklow 1992, Stainier et al. 1996). El Océano Pacífico Sur Oriental (PSO) se caracteriza por presentar una de las zonas de mínimo de oxígeno (ZMO) más intensas y someras del planeta (Farías et al. 2009). Esta se encuentra asociada a la masa de agua Ecuatorial Subsuperficial (AESS), la cual fluye en sentido paralelo a lo largo de la costa, siendo parte del sistema de contracorriente Perú-Chile. Esta es la principal fuente de nutrientes de la surgencia costera que caracteriza al sistema en la zona norte de Chile, particularmente en los $20^{\circ} \mathrm{S}$, donde se transforma en un área de surgencia permanente por el patrón de viento, y secundariamente por las características topográficas de la plataforma continental (Strub et al. 1998).

Por otra parte, en el límite superior de la ZMO, la existencia de un gran aporte de materia orgánica (MO) mediada por la actividad fotosintética, y de una surgencia permanente, favorece el desarrollo de consorcios del picoplancton heterotrófico que participan en el reciclaje del carbono, y también quimioautotrófico dependientes de amonio y otros compuestos reducidos (Galán et al. 2009, Molina \& Farias 2009). Estas comunidades microbianas (i.e., bacterias y arqueas), denominadas generalmente como bacterioplancton, tienen una posición central en el flujo de carbono, con dos principales papeles ecológicos, primero la incorporación del material orgánico e inorgánico como biomasa disponible (i.e., producción procariótica) y segundo la remineralización de la materia orgánica (i.e., respiración) (Pomeroy 1974, Fuhrman \& Azam 1982). En este contexto, los sistemas de surgencias costeros, poseen una marcada influencia de la estructura trófica microbiana (Landry 2002), mediante procesos biológicos como el pastoreo, lisis viral, exudado y material refractario lábil, este último consumido por el componente bacteriano en la ZMO (Pantoja 2006) y surgencia frente a Chile (Troncoso et al. 2003)

En esta zona de surgencia costera permanente (ZSCP) del sistema de Corrientes de Humboldt ( $\mathrm{SCH}$ ), la trama trófica planctónica está constituida por las vías clásicas y microbiana (Vargas \& González 2004), donde el bacterioplancton contribuye de manera significativa como fuente de carbono a los eslabones superiores incluidos los plancteres gelatinosos (Vargas et al. 2007), y a la mineralización de la materia orgánica. Troncoso et al. (2003) han reportado para la ZSCP del norte de Chile, uno de los valores más altos de producción secundaria $\left(1722 \pm 1362 \mathrm{mgC} \mathrm{m}^{-2} \mathrm{~d}^{-1}\right)$. Esta alta producción se sostiene sobre todo por el efecto fertilizante de la surgencia costera impulsada por el viento, que bombea nutrientes en la zona eufótica sobre la plataforma continental (Barber \& Smith 1981).

Por otra parte, el SCH está sujeto a una fuerte variabilidad interanual debido al El Niño Oscilación del Sur (ENOS) (Escribano et al 2004). El ENOS provoca cambios en el régimen estacional 'normal', generando una oxigenación mayor cerca del fondo de la columna de agua en zonas costeras someras como bahía Chipana (214's). Esto provoca un aumento de la biomasa de la macrofauna bentónica y bioperturbación de los sedimentos en asociación con la desaparición de las esteras bacterianas filamentosas (Escribano et al. 2004), así como la disponibilidad de la materia orgánica particulada para pelágicos y fauna bentónica pueden diferir a lo largo del año (Aguilera et al. 2009). Este es un factor que determinaría las fluctuaciones de la dinámica poblacional y la producción secundaria en estas zonas. Por otra parte, Steven \& Ulloa (2008) describieron importante diversidad para el dominio Bacteria, revelando un predominio de comunidades ambientales pertenecientes $\gamma$-y $\alpha$-Protebacteria y Bacteriodes.

Por otra parte, el estudio de la estructura de tamaños del plancton permite una buena aproximación para comprender la distribución de la biomasa en la caracterización del flujo de energía en el ecosistema pelágico a través de las rutas microbiana y herbívora, el balance de estas determina la capacidad del ecosistema para reciclar el carbono en las capas superficiales o exportarlo hacia aguas profundas (Legendre \& Le Févre 1989). En este contexto, la variabilidad del tamaño medio de las células del fitoplancton ha sido interpretada comoel resultado de estrategias biológicas relacionadas con la incorporación de nutrientes (Malone 1980) y también como consecuencia directa de la dinámica vertical de masas de agua (Semina 1968, 1972; Rodríguez et al. 2001).

Bahía Chipana, es considerada como zonas de surgencias costera permanente (ZSCP) del sistema de Corrientes de Humboldt (SCH) (Fonseca \& Farias 1987) en el cual se desarrollan procesos biológicos altamente productivos acotadas en escalas de espacio restringidos (Vargas et al. 2007), capaces de impulsar procesos de fertilización de la capa fótica y bajas en el contenido de oxígeno, permitiendo que los productores primarios incorporen los compuestos necesarios para realizar el proceso de fotosíntesis, que incluyen el desarrollo de las vías clásicas y microbiana (Escribano \& Morales 2004, Vargas \& González 2004), proporcionando altas cantidades de carbono, del orden del 10 al 50\% hacía eslabones superiores (McManus 
\& Peterson 1988, Vargas et al. 2007). Sin embargo se desconocen las relaciones que se generan en Bahía Chipana, entra la variabilidad ambiental y la repuesta del picoplancton heterotrófico.

La necesidad de la comprensión de los factores y mecanismos que determinan su alta productividad biológica y los fuertes efectos oceanográficos y sociales causados por el evento Niño en la región (Blanco \& Díaz 1985, Fuenzalida 1985, Kelly \& Blanco 1986; Fuenzalida 1992). En ese sentido el presente estudio describe y analiza el efecto sobre la abundancia y estructura de tamaños del picoplancton heterotrófico (bacterioplancton), a partir de los cambios en las condiciones oceanográficas de la plataforma continental de bahía Chipana frente a zonas de surgencias costera permanente (ZSCP) del sistema de Corrientes de Humboldt (SCH). Esta información se considera relevante sobre el estado fisiológico del bacterioplancton, toda vez que ha sido demostrado que éste tiende a reducir su volumen bajo condiciones adversas como limitación de nutrientes, predación o bajo fuertes condiciones de mezcla (Pulido-Villenas \& Reche 2003, Mukhanov et al. 2007), ya que su tamaño determinará en gran medida la cantidad de biomasa disponible para el ecosistema en estudio.

\section{Materiales y MÉTODOS}

Bahía Chipana está situada a $120 \mathrm{~km}$ al sur de Iquique, posee una orientación al norte, a diez kilómetros al sur de la Bahía Chipana desemboca el río Loa, el cual puede tener alguna influencia en la bahía, especialmente durante los eventos de El Niño, por incremento de su caudal debido a las precipitaciones. Esta bahía se caracteriza por eventos de surgencia costera permanente, una capa de mínimo de oxígeno siempre presente y una alta producción planctónica, donde la intensidad de la surgencia varía a escala diaria y semanal, lo cual produce efectos sobre la composición de la comunidad de fitoplancton (Herrera \& Escribano 2006, Aguilera et al. 2009). Esta área ha sido descrita como una lugar de desove para los pequeños peces pelágicos (Herrera \& Escribano 2006, Palma et al. 2006).

El área de estudio correspondió al margen costero de la plataforma continental de bahía Chipana, entre la costa y aproximadamente $10 \mathrm{~km}\left(70^{\circ} 09^{\prime} \mathrm{W}, 21^{\circ} 21^{\prime} \mathrm{S}\right)$. Se establecieron 6 estaciones, 3 paralelas a la línea de costa y sobre el margen costero, denotadas como R1, R2 y R3 ( $20 \mathrm{~m}$ de profundidad desde el piso marino y a $0,2 \mathrm{~km}$ de la zona de rompientes), $\mathrm{y}$ las otras 3 dispuestas perpendicularmente a la línea de costa a 1,86 (R7), 5,58 (R8) y 9,3 (R9) km (Fig. 1).
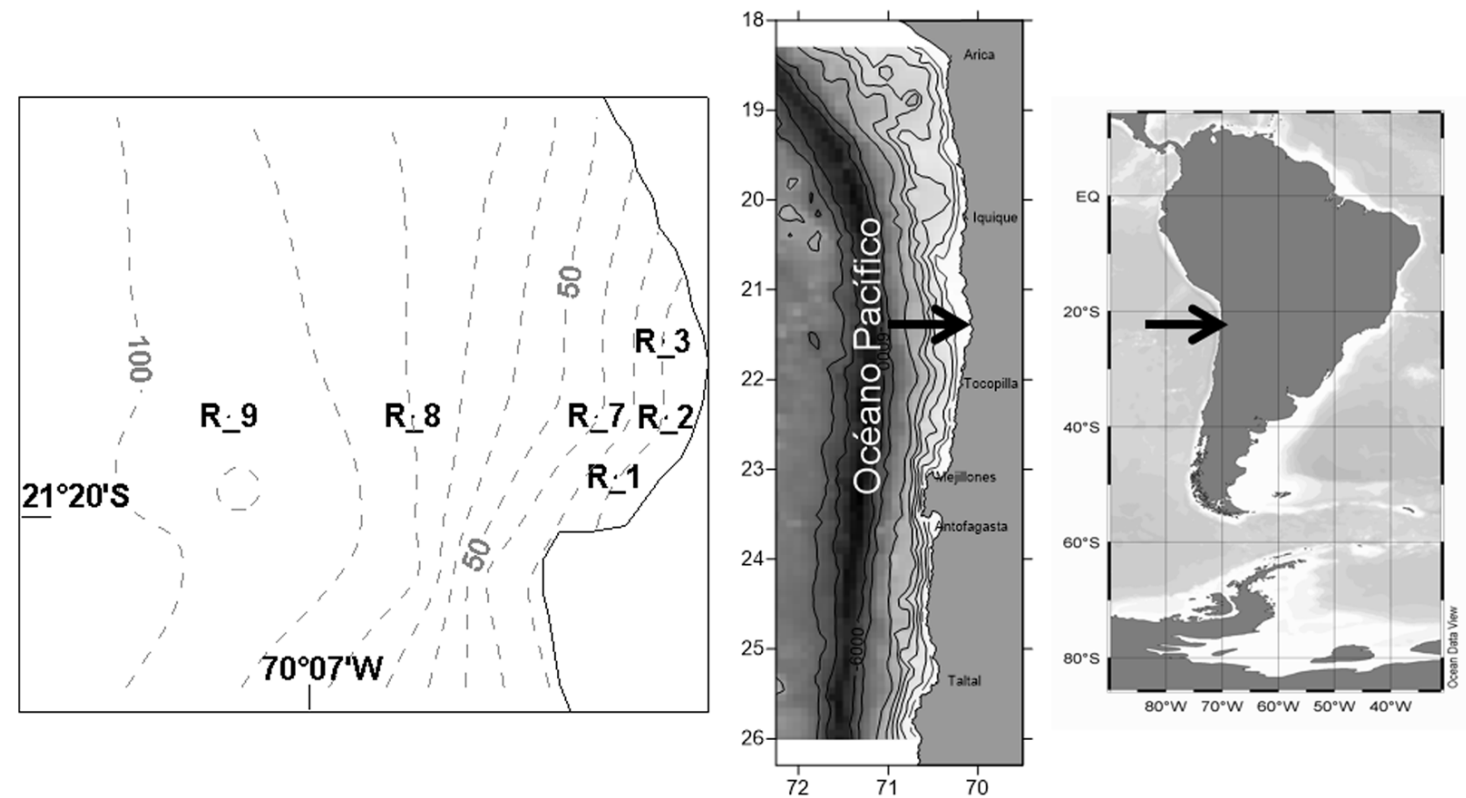

Figura 1. Área de estudio e información geográfica de los sitios de muestreos. Estaciones costeras corresponden a R1, R2 y R3, en tanto que R7, R8 y R9 conforman la transecta / Study area and geographic information of sampling station. R1, R2 and R3 correspond to shore station, and transect conformed by R7, R8 and R9 
La información microbiana y oceanográfica empleada en este estudio fue extraída de la base de datos generada por el Proyecto CENSOR (Climate variability and El Niño Southern Oscillation: Implications for Natural Coastal Resources and Management). Se analizaron las campañas llevadas a cabo en diciembre $(2004,2005,2006)$ y julio $(2005,2006,2007)$, como períodos representativas de verano e invierno, respectivamente.

Se calculó el índice de surgencia (IS) de acuerdo a Bakun (1973) con datos de velocidad del viento obtenidos en el Aeropuerto Diego Aracena, ubicado a $45 \mathrm{~km}$ al sur de la ciudad de Iquique. Debido a que los eventos de surgencia tiene un efecto acumulativo sobre la estructura y producción de un ecosistema, se empleó un índice de surgencia acumulado (ISA), el cual representa la suma de los valores diarios. Desde un punto que presentó un valor de IS cercano a 0 , así los valores más altos del índice indicarán una mayor o menor actividad de los eventos de surgencia (Bograd et al. 2009). Para las estimaciones de temperatura y salinidad se empleó un CTD SBE 19, equipado con un sensor de oxígeno disuelto (OD) SBE 43. Se emplearon botellas Niskin de $5 \mathrm{~L}$ de capacidad para la obtención de muestras de agua para el análisis del bacterioplancton, clorofila- $a$ y oxígeno disuelto (empleada en la calibración del sensor de OD), las profundidades estudiadas fueron 1, 5, 10, 25, 50 y 75 m. La concentración de clorofila$a$ se determinó mediante un fluorómetro TD-700 (Turnes Design $\left.^{\odot}\right)$, empleando filtros de fibra de vidrio $(0,7 \mu \mathrm{m}$ de poro), por los cuales se filtró $250 \mathrm{~mL}$ de muestra, las cuales fueron extraídos en acetona (90\%), de acuerdo a Parsons et al. (1984), la concentración de oxígeno a través del método de Winkler (Carpenter 1965).

Las muestras para bacterioplancton, fueron inmediatamente fijadas con formaldehido tamponado con una solución de fosfato salino para obtener una concentración final de un $1 \%$ (v/v), y mantenidas en oscuridad a una temperatura de $4-5^{\circ} \mathrm{C}$ hasta su posterior análisis. Luego $2 \mathrm{~mL}$ de muestras (pre filtrada por una malla estéril de $10 \mu \mathrm{m}$ de poro) fueron teñidos con 4'-6diamino-2-fenilindol (DAPI, concentración final 0,01 $\mathrm{mg} \mathrm{ml}^{-1}$ ), filtrada en una membrana de policarbonato negra $(0,2 \mathrm{~mm}$ de poro, $25 \mathrm{~mm}$ de diámetro), montada en un portaobjeto y congelado a $-20^{\circ} \mathrm{C}$, hasta su posterior análisis al microscopio de fluorescencia equipado con cubo de filtros $(\gamma$ excitación $\sim 359 \mathrm{~nm}, \lambda$ emisión $\sim 461 \mathrm{~nm}$ ).

La enumeración y medición del picoplancton se realizó en un microscopio de epifluorescencia (Leitz $\left.{ }^{\circledR}\right)$, equipado con una cámara de alta sensibilidad, conectada a un computador. Por cada campo se contaron entre 50 y 300 células, completando un total entre 20 y 30 microfotografías por muestra ( 800 dpi de resolución). Cada imagen fue procesada en el software Image $^{1}$. Para la calibración de las mediciones se emplearon esferas de latex fluorescentes de 0,2 mm de tamaño (Polyscience Inc., USA) y una regleta micrométrica $(0,001 \mathrm{~mm}$ de precisión). Para obtener el número de células, y los tamaños, cada imagen fue procesada de acuerdo al protocolo propuesto por Massana et al. (1997). El volumen celular para cada partícula fue calculado de acuerdo a Fry (1988), para estimar la biomasa procariota se utilizó una función alométrica entre contenido de carbono y volumen celular de acuerdo a lo propuesto por Loferer-Krößbacher et al. (1998), para el fluorocromo DAPI. Para el análisis de la estructura de tamaños se estimó la longitud máxima de 500 a 1000 células por muestra, subdividiendo el bacterioplancton en las siguientes clases de tamaño: $<0,4 ; 0,4-0,8 ; 0,8-1,2 ; 1,2-1,6 ; 1,6-2,0 ; 2,0-2,4$ y $>2,4$ (Pernthaler et al. 1996), ya que según estos autores esto permite detectar con mayor resolución pequeñas diferencias en los tamaños de las partículas picoplanctónicas.

Para el análisis de la información derivada del bacterioplancton y su relación con las variables ambientales se emplearon dos estrategias. En la primera, la relación entre las variables respuesta: abundancia procariota y volumen celular, versus las variables predictivas: temperatura, salinidad, frecuencia de Brunt-Väisälä (Bode \& Fernández 1992), oxígeno disuelto y clorofila- $a$ total, las que fueron analizada empleando modelos aditivos generalizados (GAMs). Las variables respuestas fueron analizadas de manera independiente, y en cuanto a las variables predictoras se emplearon diferentes interacciones. Para seleccionar la interacción con el mejor ajuste se utilizó Criterio de Información de Akaike (AIC). Los análisis fueron realizados con el paquete 'mgcv' bajo el ambiente del programa R (Wood 2006).

La segunda estrategia estuvo referida a la distribución de tamaños de bacterioplancton y su relación con las variables oceanográficas. Para esto la información microbiológica fue ordenada en un arreglo matricial y analizado en el modo Q. Esta fue reducida a un arreglo triangular a través del índice de distancia de Bray-Curtis. La matriz de disimilitud fue analizada yresumida a través de un escalamiento multidimensional (MDS), para lo cual los datos originales fueron transformados a la raíz cuarta. Para evaluar la consistencia de los grupos formados del análisis previo, se llevó a cabo un análisis de similitud o ANOSIM (Clarke \& Gorley 2006). Este mismo análisis se aplicó para determinar diferencias entre periodos de muestreo y profundidad en cada estación. Se realizó un análisis SIMPER para establecer el aporte de cada clase de tamaño a la estructura comunitaria generada (Clarke \& Gorley 2006).

${ }^{1}<$ http://rsb.info.nih.gov/il/> 
A
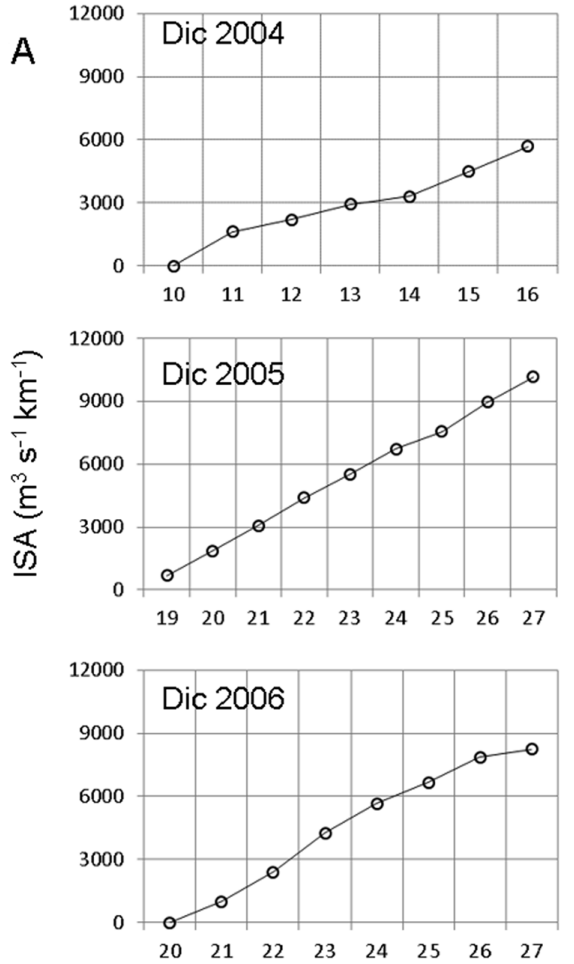
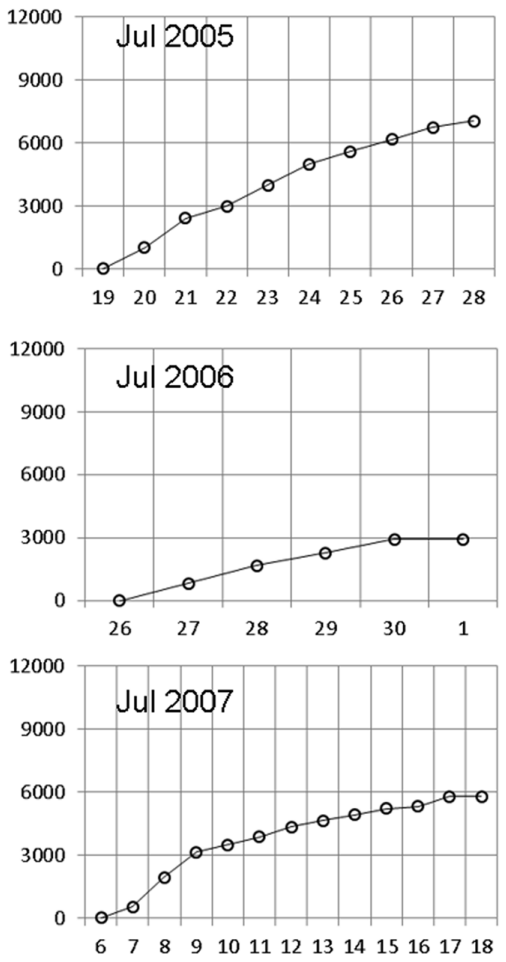

B

Anomalias TSM Iquique

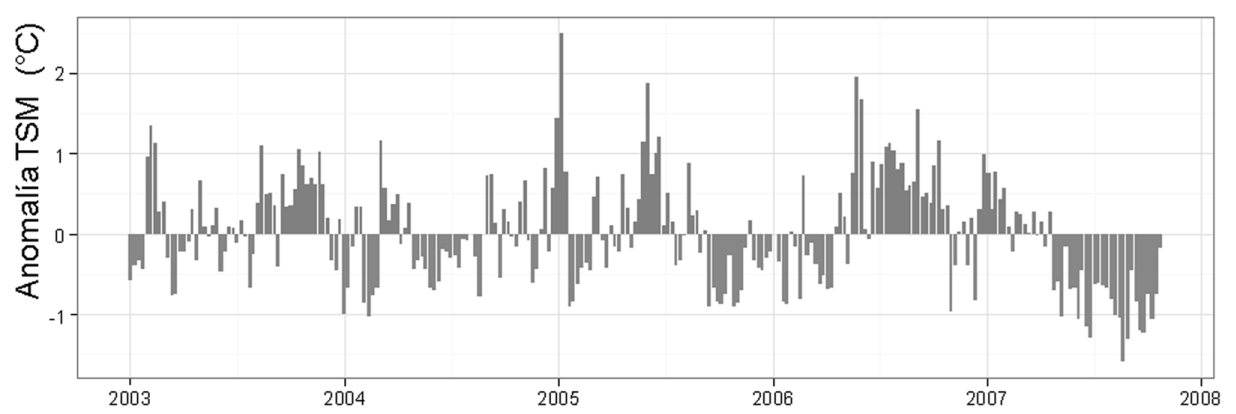

Figura 2. A) Índice de Surgencia Acumulado (ISA) calculado como la suma de los valores diarios previo a cada campaña. B) Progresión de las anomalías de las TSM en bahía Iquique (Fuente: Servicio Hidrográfico de la Armada de Chile) / A) Accumulated Upwelling Index (ISA) calculated as the sum of the prior to each campaign daily values. B) Progression of SST anomalies in lquique Bay (Source: Servicio Hidrográfico de la Armada de Chile)

\section{Resultados}

\section{CONDICIONES OCEANOGRÁFICAS}

Sobre la plataforma continental frente a bahía Chipana, se observó una columna de agua dividida en 2 capas (especialmente en las estaciones 7, 8 y 9). Una capa superficial, delimitada por la termoclina, de un espesor que fluctuó entre $\operatorname{los} 10 \mathrm{y} 40 \mathrm{~m}$, caracterizada por una mayor variabilidad temporal en sus propiedades, i.e., temperaturas más altas $\left(>14^{\circ} \mathrm{C}\right)$, menores salinidades $(<34,7)$ y condiciones óxicas $(>4,5 \mathrm{~mL}$ $\mathrm{L}^{-1}$ ) (Figs. 2 y 3). La capa subsuperficial, delimitada por la base de la termoclina caracterizada por una menor variabilidad temporal, la que se expresan en menores temperaturas $\left(<14^{\circ} \mathrm{C}\right)$, en una mayor salinidad $(<34,9)$ y con condiciones mayoritariamente hipóxicas $\left(<2,0 \mathrm{mLL}^{-1}\right)$ (Figs. 2 y 3 ). En las estaciones situadas cerca del margen costero, las condiciones oceanográficas fueron similares a lo observado en la capa superficial de las estaciones perpendiculares a la costa, estas presentaron menores temperaturas y niveles $<1 \mathrm{mLL}^{-1} \mathrm{de} \mathrm{OD}$ en algunas de las campañas, como por ejemplo la de diciembre 2005. 


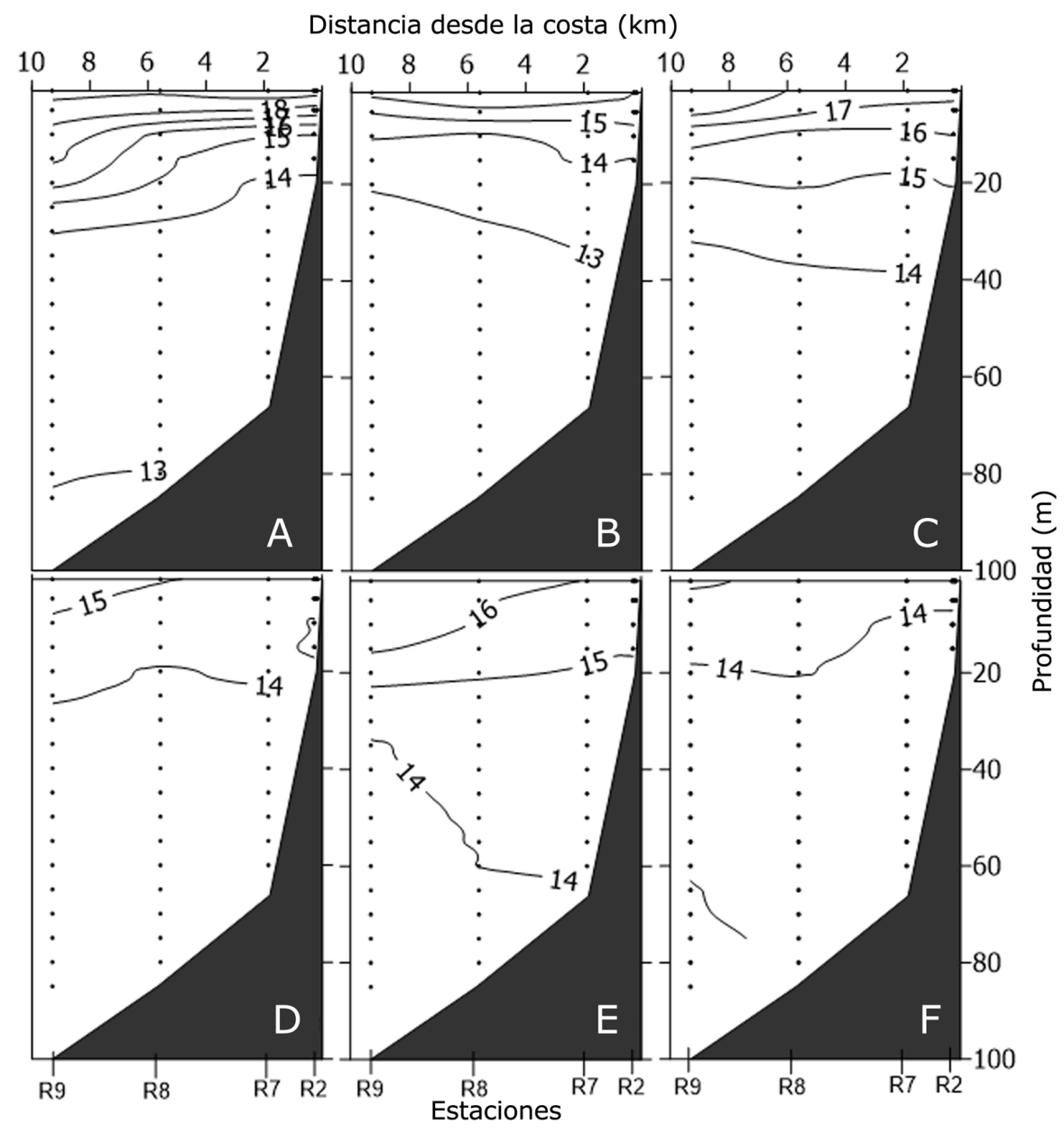

Figura 3. Distribución vertical de temperatura ( $\left.{ }^{\circ} \mathrm{C}\right)$. A) 16 diciembre 2004, B) 27 diciembre 2005, C) 27 diciembre 2006, D) 28 julio 2005, E) 01 julio 2006, F) 18 julio 2007 / Vertical distribution of temperature $\left({ }^{\circ} \mathrm{C}\right)$. A) December 16 2004, B) December 27 2005, C) December 27 2006, D) July 28 2005, E) July 01 2006, F) July 182007

La variabilidad observada en la estructura física de la columna de agua estuvo asociada a la ocurrencia de eventos de surgencia. Estos eventos pueden efectivamente impactar en el margen costero, pero además tienen un efecto acumulativo. La Figura 2A muestra la evolución del ISA, donde los muestreos llevados a cabo en diciembre 2005 y 2006, y julio 2005 fueron realizados bajo condiciones de surgencia activa, en cambio la campaña de julio 2006 presentó el ISA más bajo de la serie. Para diciembre 2004 y julio 2007 las condiciones se consideraron moderadas (Bograd et al. 2009). Desde el punto de la estacionalidad del sistema, destacan de la estructura termal las condiciones observadas en los inviernos del 2006 y 2007 , el primero presentó una condición más cálida de lo normal, con anomalías positivas superiores a $1,5^{\circ} \mathrm{C}$. Al contrario, durante el 2007 se observaron condiciones más frías con anomalías negativas de $-1,5^{\circ} \mathrm{C}$. (Fig. 2B). También destacan las condiciones detectadas durante diciembre 2004, con las mayores temperaturas de todo el periodo de estudio (Fig. 2B). Verticalmente, la estructura termal se caracterizó por presentar mayores gradientes en las campañas realizadas en diciembre que las realizadas en julio, destacándose la de diciembre 2004, donde se detectaron los mayores gradientes y las mayores temperaturas (Fig. 3). En tanto, en las campañas de julio se observó una columna de agua más homogénea, destacándose la de julio 2006 con mayores temperaturas a consecuencia de la ocurrencia del evento El Niño (Fig. 3E), en contraste a la de julio 2007 realizada bajo condiciones La Niña (Fig. 3F). 
Los niveles de OD mostraron una capa superficial oxigenada, con valores superiores a $5 \mathrm{~mL} \cdot \mathrm{L}^{-1}$, la oxilínea de $1 \mathrm{~mL} \cdot \mathrm{L}^{-1}$ (límite superior de la ZMO) se encontró a profundidades entre los 10 y $30 \mathrm{~m}$, profundizándose en las estaciones más alejadas de la costa, lo que se observó en diciembre 2004, julio 2005 y diciembre 2006 (Fig. 4). Una columna de agua moderadamente oxigenada (con valores cercanos a $3 \mathrm{~mL} \cdot \mathrm{L}^{-1}$ ), fue detectada en julio 2006, y los menores niveles de OD en diciembre 2005, destacando que el tope de la ZMO se encontró a $10 \mathrm{~m}$ de profundidad en toda la sección (Fig. 4). La biomasa fitoplanctónica mostró fluctuaciones anuales significativas, como se aprecia en la Figura 5. Durante las campañas del diciembre 2004, julio y diciembre 2005 se detectaron concentraciones > $10 \mu \mathrm{g} \mathrm{Cla} \mathrm{L}{ }^{-1}$, especialmente en superficie y cercano al borde costero. A contar del 2006 se observó una declinación con niveles $<10 \mu \mathrm{g} \mathrm{Cla} \mathrm{L}^{-1}$, para llegar a las menores concentraciones en julio 2007, < 1,5 $\mu \mathrm{g} \mathrm{Cla} \mathrm{L}^{-1}$ (Fig. 5).

\section{Distancia desde la costa $(\mathrm{km})$}

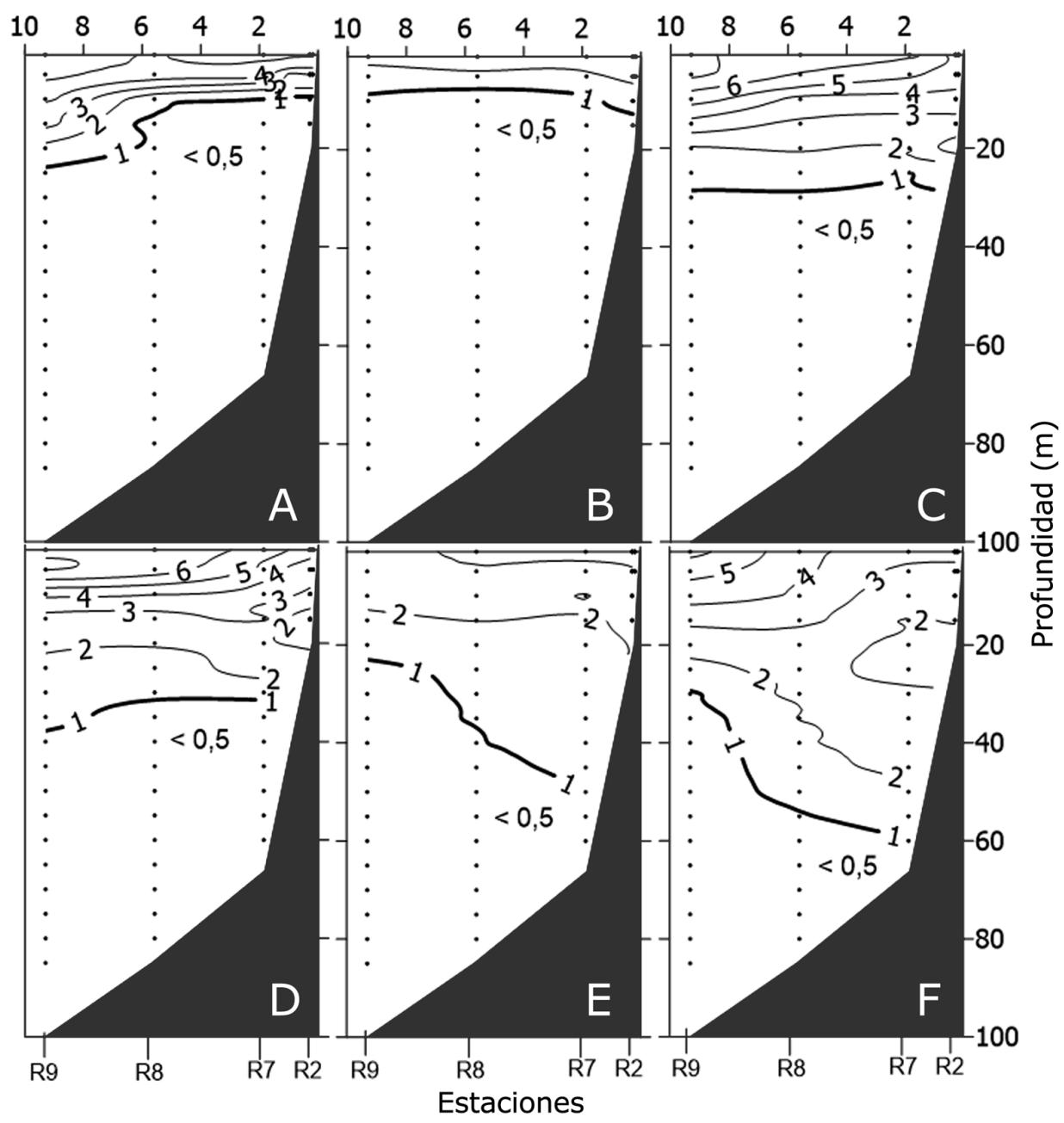

Figura 4. Distribución vertical de oxígeno disuelto $\left(\mathrm{mL} \mathrm{L}^{-1}\right)$. A) 16 diciembre 2004, B) 27 diciembre 2005, C) 27 diciembre 2006, D) 28 julio 2005, E) 01 julio 2006, F) 18 julio 2007 / Vertical distribution of dissolved oxygen ( $\mathrm{mL} \mathrm{L}^{-1}$ ). A) December 16 2004, B) December 27 2005, C) December 27 2006, D) July 28 2005, E) July 01 2006, F) July 182007 


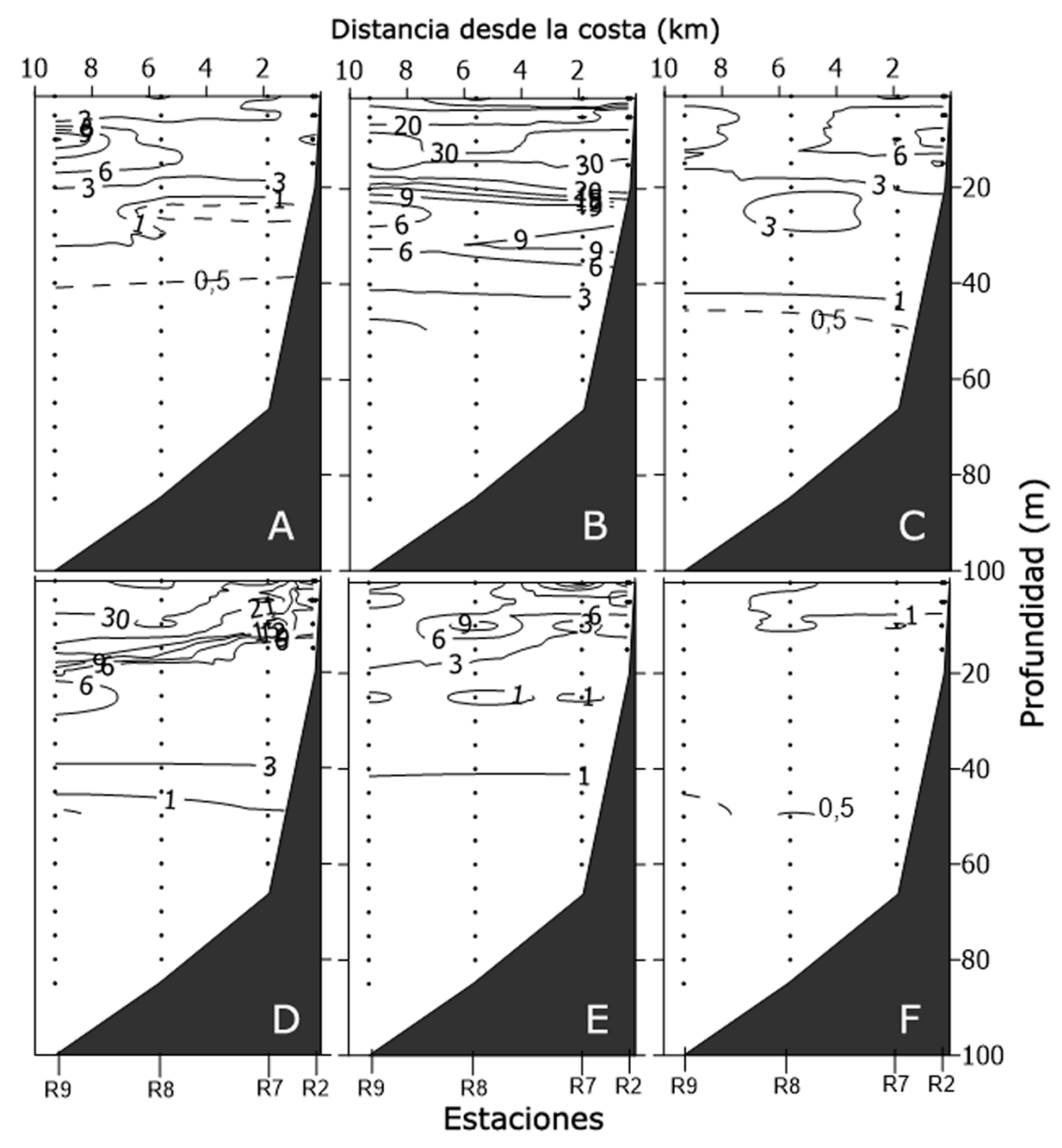

Figura 5. Distribución vertical de clorofila-a $\left(\mu \mathrm{g} \mathrm{L}^{-1}\right)$. A) 16 diciembre 2004, B) 27 diciembre 2005, C) 27 diciembre 2006, D) 28 julio 2005, E) 01 julio 2006, F) 18 julio 2007 / Vertical distribution of chlorophyll-a ( g L $\left.^{-1}\right)$. A) December 16 2004, B) December 27 2005, C) December 27 2006, D) July 28 2005, E) July 01 2006, F) July 182007

\section{Abundancia, volumen celular y estructura de TAMAÑOS DEL BACTERIOPLANCTON}

La abundancia procariota (AP) mostró diferencias de hasta dos órdenes de magnitud entre campañas, lo cual se ve reflejado al comparar los valores máximos y mínimos de las campañas de diciembre del $2006\left(7,83 \log\right.$ cél $\left.\mathrm{L}^{-1}\right)$ y diciembre del 2004 $\left(9,71 \log\right.$ cél $\left.\mathrm{L}^{-1}\right)$. Las dos primeras campañas presentaron en promedio valores más altos (diciembre 2004 y julio 2005), destacando que las mayores abundancias se detectaron en las estaciones más cercanas al margen costero (9,71 y 9,69 log cél L L ${ }^{-1}$ diciembre 2004 y julio 2005 , respectivamente). En tanto que se observó una importante variabilidad costa-océano la cual no mostró un patrón definido, así las campañas julio 2006 y 2007 se caracterizaron por que en la primera las abundancias aumentan en las estaciones más cercanas al margen costero, mientras que en la segunda se observa una fuerte disminución en sus valores costa a fuera (Fig. 6A).

El empleo de modelos generalizados aditivos, no tuvo la intención de generar predicciones, sino el emplear algunos de sus índices (i.e., devianza explicada por el modelo y el criterio de información de Akaike), para identificar la significancia de los efectos de cada variable y de las interacciones entre ellas. En la Tabla 1, se aprecia que la salinidad, estabilidad y biomasa del fitoplancton tienen un efecto significativo sobre la AP. En cuanto a las interacciones entre las variables predictoras, el modelo que incluyo salinidad, OD y clorofila $a$, explicó un $38,5 \%$ de la devianza en el ajuste del modelo, aunque este valor no fue el más alto calculado, de acuerdo al valor de AIC es el que presenta la mayor bondad de ajuste. 

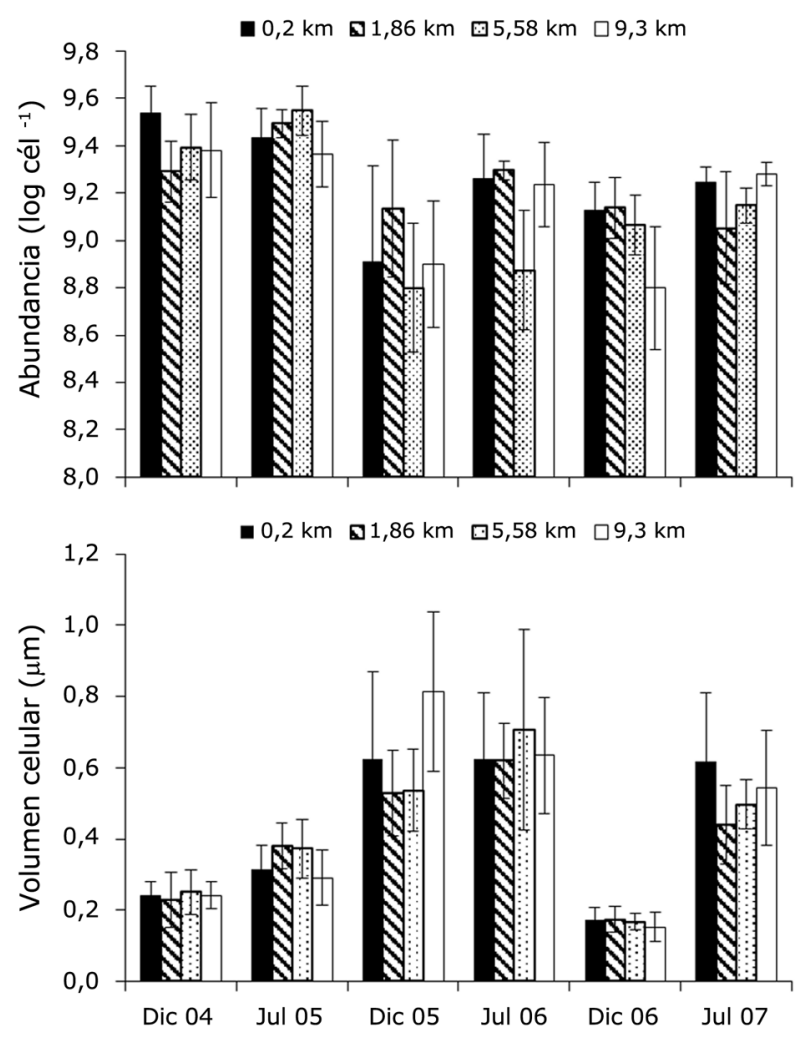

Figura 6. Distribución temporal. A) Abundancia del bacterioplancton (cel $\left.\mathrm{L}^{-1}\right)$ y B) volumen celular $\left(\mu \mathrm{m}^{3}\right)$. Barras de error corresponden a una desviación estándar / Temporal distribution. A) baterioplankton abundance (cell $\mathrm{L}^{-1}$ ), and $\mathrm{B}$ ) cell volume $\left(\mu \mathrm{m}^{3}\right)$. Error bars correspond to one standard deviation

Tabla 1. Relación entre la abundancia bacteriana (variablesrespuestas) y las variables predictivas: temperatura (Tem), salinidad (Sal), frecuencia de Brunt-Väisälä (FBV), oxígeno disuelto (OD), y clorofila-a (Cla) por fracciones y total, descrita mediante el empleo de modelos aditivos generalizados (GAMs) / Relationship between bacterial abundance (response variables) and the predictor variables: temperature (Tem), salinity (Sal), Brunt-Väisälä frequency (VSF), dissolved oxygen (DO), and chlorophyll-a (Cla) for fractions and complete, described by using generalized additive models (GAMs)

\begin{tabular}{cccccccc}
\hline Modelo & Variable & e.d.f. & $P$ & Dev. Ex. & GCV & N & AIC \\
\hline Tem & Tem & n.s. & $>0,05$ & 0,1 & $1,02 \mathrm{E}+18$ & 87 & 3856,142 \\
Sal & Sal & 1,3 & 0,026 & 8,6 & $9,37 \mathrm{E}+17$ & 87 & 3848,981 \\
FBV & FBV & 1,0 & 0,041 & 4,8 & $9,69 \mathrm{E}+17$ & 87 & 3851,952 \\
OD & OD & n.s. & $>0,05$ & 4,4 & $9,74 \mathrm{E}+17$ & 87 & 3852,375 \\
Cla $>20$ & Cla & 4,7 & 0,000 & 28,7 & $7,93 \mathrm{e}+17$ & 87 & 3834,201 \\
Tem+Sal & Tem & 7,0 & 0,013 & 32,8 & $8,67 \mathrm{E}+17$ & 87 & 3838,641 \\
& Sal & 2,5 & 0,015 & & & & \\
Sal+OD+Cla & Sal & 1,0 & 0,000 & 38,5 & $7,08 \mathrm{E}+17$ & 87 & 3824,098 \\
& OD & 3,0 & 0,013 & & & & \\
& Cla & 2,1 & 0,001 & & & & \\
\hline
\end{tabular}

GCV: Valor de validación cruzada general; AIC: Criterio de Información de Akaike; Dev. Ex.: Devianza explicada por el modelo; e.d.f.: grados de libertad efectivos. n.s.: no Ex.: Devianza
significativo
Por otra parte, los mayores volúmenes celulares se asociaron a menores abundancias, lo cual fue más marcado en diciembre 2005 (Fig. 6). Se observó un aumento del volumen en las campañas realizadas en diciembre 2004, julio 2005 y diciembre 2005 (0,15-0,36 y 0,36-1,18 $\mu \mathrm{m}^{3}$, respectivamente), con una fuerte disminución en julio y diciembre 2006, y en julio 2007 alcanzar valores semejantes a las primeras campañas $(0,28$ $1,00 \mu \mathrm{m}^{3}$ ). En la Tabla 2 se muestran los resultados de los GAMs, donde se aprecia que la temperatura y el OD tienen un efecto significativo sobre el volumen celular del picoplancton. En cuanto a las interacciones entre las variables predictoras, el modelo que incluyó salinidad, OD y clorofila total, explicó en un $37 \%$ la devianza en el ajuste del modelo, aunque este valor no fue el más alto calculado, de acuerdo al valor de AIC es el que presenta la mejor bondad de ajuste (Tabla 2).

La estructura de tamaño del bacterioplancton en bahía Chipana fue dominada por células en el rango entre 0,4-0,8 y 0,8-1,2 $\mu \mathrm{m}$ de longitud (o diámetro en el caso de células esféricas, Fig. 7). Espacialmente, no se observaron cambios significativos $(P>0,01)$ con la profundidad ni respecto de la distancia desde la costa, lo que se extiende a todos los estratos de tamaño, sin embargo en el tiempo la estructura de tamaños cambio significativamente $(P<0,01)$, cambio relacionado a una reducción en los porcentajes de contribución de las marcas de clase dominantes entre las diferentes campañas asociado a un aumento de los rangos de tamaños mayores a $2 \mu \mathrm{m}$ de longitud.

Tabla 2. Relación entre el volumen celular (variables respuestas) y las variables predictivas: temperatura (Tem), salinidad (Sal), frecuencia de Brunt-Väisälä (FBV), oxígeno disuelto (OD), y clorofila-a (Cla) por fracciones y total, descrita mediante el empleo de modelos aditivos generalizados (GAMs) / Relationship between cell volume (response variables) and the predictor variables: temperature (Tem), salinity (Sal), Brunt-Väisälä frequency (VSF), dissolved oxygen (DO), and chlorophyll-a (Cla) for fractions and complete, described by using generalized additive models (GAMs)

\begin{tabular}{cccccccc}
\hline \multirow{2}{*}{ Modelo } & Variable & e.d.f. & $P$ & Dv. Ex. & GCV & N & AIC \\
\hline Tem & Tem & 5,53 & 0,012 & 22,0 & 0,041 & 87 & $-28,50$ \\
Sal & Sal & 1,00 & 0,121 & 2,8 & 0,046 & 87 & $-18,41$ \\
OD & OD & 6,29 & 0,011 & 22,9 & 0,042 & 87 & $-27,96$ \\
Tem+Sal+OD+Cla & Tem & 5,61 & 0,054 & 50,9 & 0,034 & 87 & $-48,74$ \\
& Sal & 1,00 & 0,002 & & & & \\
& OD & 6,91 & 0,002 & & & & \\
Sal+OD+Cla & Cla & 1,00 & 0,027 & & & & \\
& Sal & 1,00 & 0,004 & 37,0 & 0,036 & 87 & $-40,45$ \\
& OD & 6,81 & 0,000 & & & & \\
& Cla & 1,00 & 0,009 & & & & \\
& & & & & & & \\
\end{tabular}

GCV: Valor de validación cruzada general; AIC: Criterio de Información de Akaike; Dev. Ex.: Devianza explicada por el modelo; e.d.f.: grados de libertad efectivos. n.s.: no significativo 


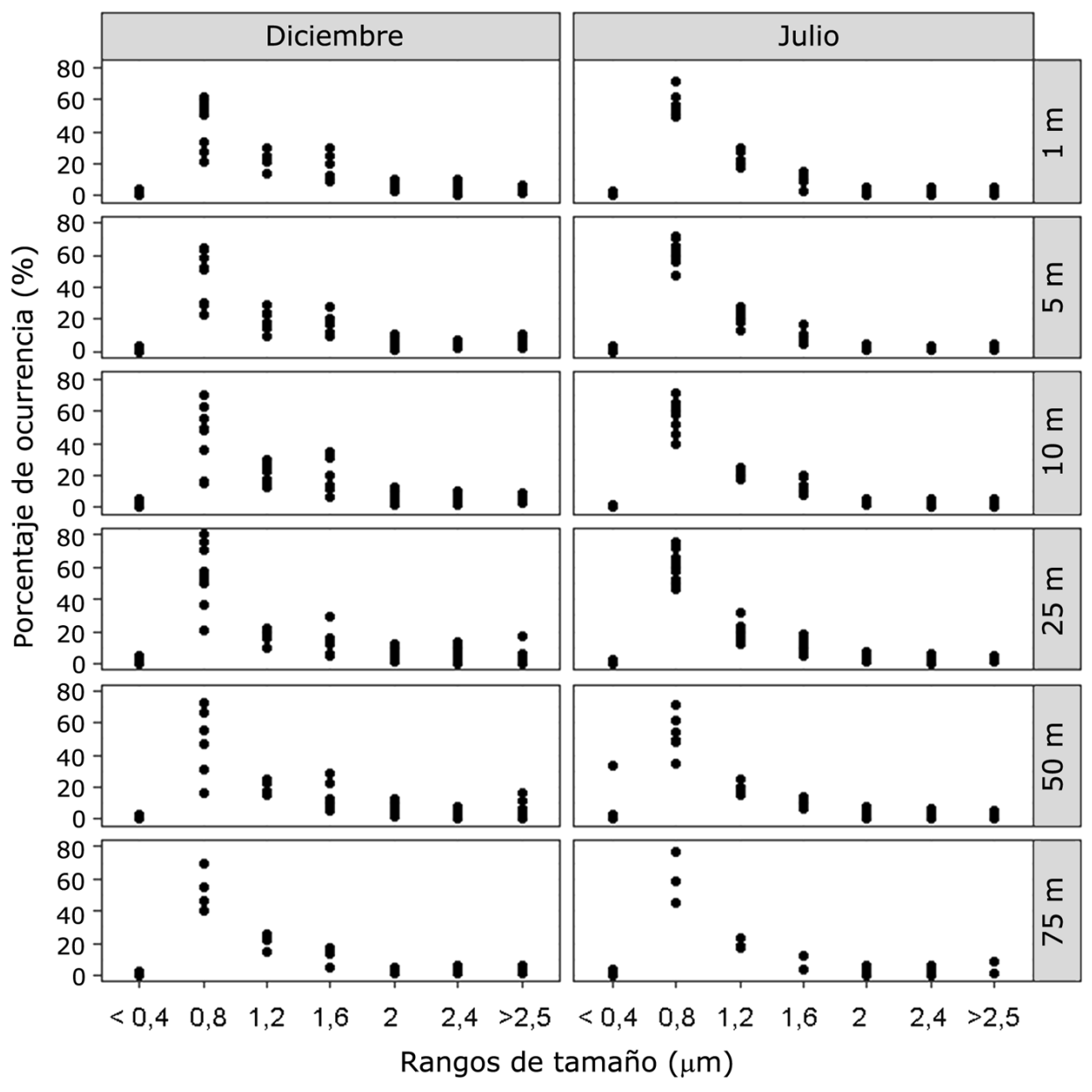

Figura 7. Distribución vertical de las clases de tamaño del bacterioplancton (\%). Columnas agrupan todo los datos de las campañas de diciembre y julio por profundidad (filas). Etiquetas en el eje derecho indican profundidad ( $m$ ) / Vertical distribution class size of bacterioplankton (\%). Column including all data by depth for December and July campaigns (row). Labels to the right axe correspond to depth (m)

Lo anterior es confirmado por los resultados del MDS que se observan en la Figura 8, donde se visualizan en forma clara los cambios en la estructura de tamaños en las campañas correspondientes a diciembre 2004 a julio 2005. En la Tabla 3 se muestran los resultados del ANOSIM, el cual reafirma las relaciones antes descritas, destacando que la campaña de diciembre 2006 fue en cuanto a la estructura de tamaño, diferente a todas las demás, al contrario las campañas de diciembre 2004 y julio 2007, que fueron muy similares entre sí. Las diferencias estuvieron relacionadas al aporte porcentual de cada rango de tamaño, así la Tabla 4 muestran los resultados obtenidos del análisis SIMPER, donde diciembre 2004 como julio 2007 tuvieron la misma contribución porcentual (>60\%), en cambio diciembre 2006 presentó partículas entre 1,6 y 2,4 $\mu$ m con una contribución importante (>14\%), y lo más notable es que la clase de 0,4 a $0,8 \mu$ m alcanzó un 30\%, el más bajo de todo el periodo de estudio.

Tabla 3. Evaluación de la consistencia de losgrupos formados mediante un ANOSIM / Evaluating consistency of the groups formed by ANOSIM

\begin{tabular}{lcrcrl}
\hline Prueba de Parejas & Jul05 & Dec05 & \multicolumn{1}{c}{ Jul06 } & Dec06 & \multicolumn{1}{c}{ Jul07 } \\
\hline Dec04 & $0,302^{*}$ & $0,885^{* *}$ & $0,445^{*}$ & $0,996^{* *}$ & 0,079 \\
Jul05 & & $1,000^{* *}$ & $0,869^{* *}$ & $1,000^{* *}$ & $0,598^{*}$ \\
Dec05 & & & $0,352^{*}$ & $0,981^{* *}$ & $0,998^{* *}$ \\
Jul06 & & & & $0,768^{* *}$ & $0,747^{* *}$ \\
Dec06 & & & & & $0,994^{* *}$ \\
\hline
\end{tabular}

R Global $=0,713 ; P<0,01 ; *: P<0,05 ; * *: P<0,01$;

Valores de $\mathrm{R}$ categorizados en 3 grupos: $\mathrm{R}>0,75$ : indica que los cruceros estuvieron bien separados. $\mathrm{R}>0,5$ : indican clara diferencia, pero los cruceros se sobreponen. $\mathrm{R}<0,25$ : indica que no hay diferencias y que los cruceros son completamente divisibles 


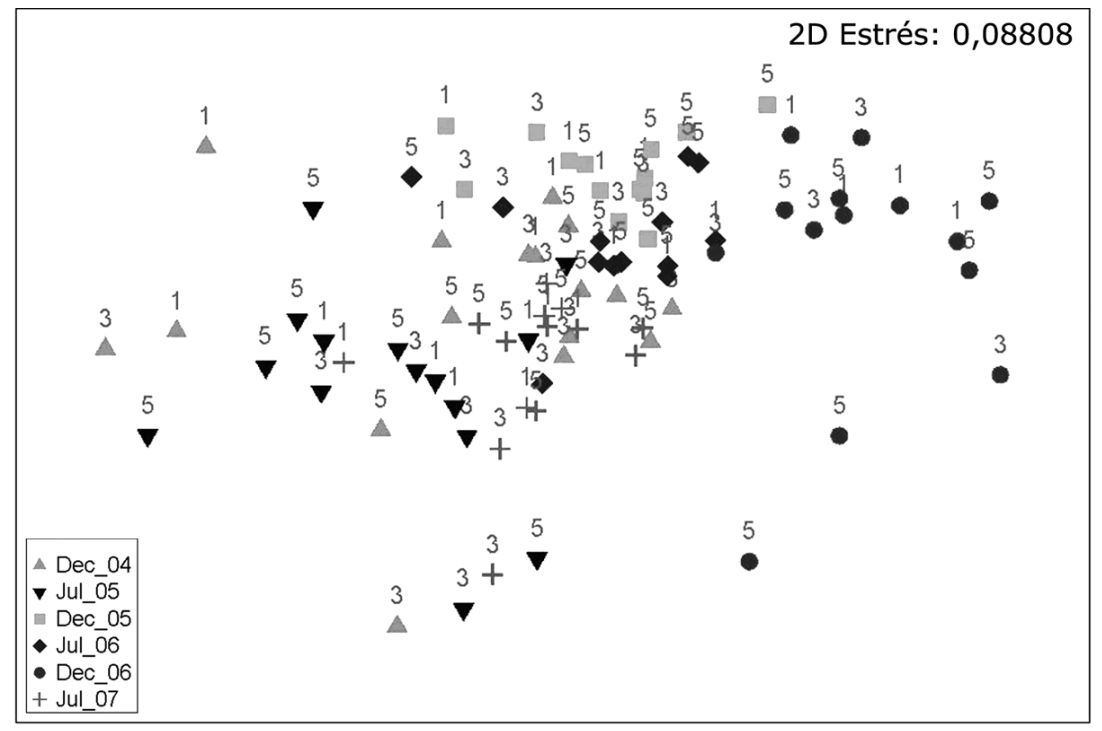

Figura 8. Ordenación por escalamiento multidimensional mediante el índice de similitud de Bray-Curtis, análisis en modo $Q$ de los diferentes períodos de muestreo / Ordination by multidimensional scaling of Bray-Curtis similarities in the $Q$ mode of different sampling periods

\section{Discusión}

Los resultados presentados sugieren que el tamaño celular del bacterioplancton, así como también su abundancia, sufren variaciones temporales que se relacionan principalmente a factores físicos. Además, el tamaño celular de las bacterias presenta una correspondencia con la tasa de crecimiento, la que a su vez depende de la condición de nutrientes, o fuentes de carbono, disponibles en el ambiente que habita el microorganismo (Azam et al. 1983). En estudios realizados en bacterias evolutivamente similares y distantes, se pudo comprobar que la limitación de un nutriente a largo plazo conduce a la presencia de una población heterogénea en tamaño, en la que el diámetro medio se reduce en un $\sim 40 \%$ (Chien et al. 2012). Esto indica que la estructura comunitaria del bacterioplancton es el resultado de respuestas fisiológicas y ecológicas a estímulos ambientales dinámicos y fluctuantes, de manera que comprender los mecanismos que allí operan permite explicar y predecir los cambios en estructura de tamaño, en función de la disponibilidad de nutrientes, irradiación, profundidad de la capa de mezcla entre otros, elementos que inciden en las tasas metabólicas y en los mecanismos de división celular (Mukhanov et al. 2007). En este estudio los mayores valores de abundancia se detectaron en las campañas de diciembre 2004 y julio 2005, los cuales se relacionan a menores volúmenes celulares, sin embargo no fue posible observar una tendencia estacional en su variabilidad (Fig. 6A y B). Los datos obtenidos sugieren que la abundancia del bacterioplancton responde a fluctuaciones que pueden tener su origen en el ambiente físico (variabilidad sinóptica y de submesoescala de la surgencia) o que pueden estar relacionados a procesos biológicos como disponibilidad de materia orgánica derivada del fitoplancton (del cual la concentración de clorofila- $a$ es un proxy). También el ambiente químico es de importancia, donde el contenido de oxígeno disuelto es un factor limitante verticalmente del bacterioplancton aeróbico.

\section{VARIABILIDAD AMBIENTAL Y RESPUESTA DE LA ABUNDANCIA DEL BACTERIOPLANCTON}

Para establecer algún grado de relación entre el bacterioplancton yel ambiente físico-químico se empleó una primera aproximación estadística, empleando modelos aditivos generalizados (GAM). En nuestro caso, se establece que la abundancia depende de factores que no son los mismos para el volumen celular (Tablas 1 y 2). Por un lado, la abundancia del bacterioplancton mostró una mayor relación con la salinidad, y ninguna relación significativa con la temperatura y la biomasa fitoplanctónica (Tabla 1). Este tipo de método estadístico permitió explorar de manera más robusta la relación entre las variables. Se debe mencionar que la exploración inicial a través de los métodos tradicionales e históricos como la regresión lineal simple, correlación e incluso la transformación log de los datos, no 
Tabla 4. Análisis SIM PER para establecer el aporte de cada clase de tamaño a la estructura comunitaria generada / SIMPER analysis to establish the contribution of each size class to the community structure generated

\begin{tabular}{|c|c|c|c|c|c|}
\hline \multicolumn{2}{|c|}{ Diciembre 2004} & \multicolumn{2}{|c|}{ Julio 2005} & \multicolumn{2}{|c|}{ Diciembre 2005} \\
\hline \multicolumn{2}{|c|}{ Similitud promedio: 90,34} & \multicolumn{2}{|c|}{ Similitud promedio: 94,40} & \multicolumn{2}{|c|}{ Similitud promedio: 95,17} \\
\hline Clase & $\begin{array}{c}\text { Contribución } \\
(\%)\end{array}$ & Clase & $\begin{array}{c}\text { Contribución } \\
(\%)\end{array}$ & Clase & $\begin{array}{c}\text { Contribución } \\
(\%)\end{array}$ \\
\hline $0,4-0,8$ & 63,1 & $0,4-0,8$ & 69,49 & $0,4-0,8$ & 57,63 \\
\hline $0,8-1,2$ & 20,83 & $0,8-1,2$ & 20,28 & $0,8-1,2$ & 14,68 \\
\hline \multirow[t]{3}{*}{$1,2-1,6$} & 9,13 & $1,2-1,6$ & 6,57 & $1,2-1,6$ & 11,79 \\
\hline & & & & $>2,4$ & 4,95 \\
\hline & & & & $1,6-2,0$ & 4,54 \\
\hline \multicolumn{2}{|c|}{ Julio 2006} & \multicolumn{2}{|c|}{ Diciembre 2006} & \multicolumn{2}{|c|}{ Julio 2007} \\
\hline \multicolumn{2}{|c|}{ Similitud promedio: 91,06} & \multicolumn{2}{|c|}{ Similitud promedio: 88,25} & \multicolumn{2}{|c|}{ Similitud promedio: 95,00} \\
\hline Clase & $\begin{array}{c}\text { Contribución } \\
(\%)\end{array}$ & Clase & $\begin{array}{c}\text { Contribución } \\
(\%)\end{array}$ & Clase & $\begin{array}{c}\text { Contribución } \\
(\%)\end{array}$ \\
\hline $0,4-0,8$ & 52 & $0,4-0,8$ & 30,95 & $0,4-0,8$ & 60,25 \\
\hline $0,8-1,2$ & 21,35 & $0,8-1,2$ & 25,12 & $0,8-1,2$ & 23,32 \\
\hline $1,2-1,6$ & 13,53 & $1,2-1,6$ & 22,74 & $1,2-1,6$ & 10,05 \\
\hline \multirow[t]{2}{*}{$1,6-2,0$} & 4,56 & $1,6-2,0$ & 7,61 & & \\
\hline & & $2,0-2,4$ & 7,47 & & \\
\hline
\end{tabular}

mostraron relaciones significativas. Los GAM fueron diseñados para modelar relaciones no lineales, y se han aplicado en diversas áreas de las ciencias ambientales. No obstante, estos resultados no concuerdan con los reportado por otros autores (e.g., Abarzúa et al. 1995, Troncoso et al. 2003), donde destacan una relación significativa entre fitoplancton y bacterioplancton. Por otra parte Eissler et al. (2010) muestran la ausencia de una relación lineal entre las variables de origen fitoplanctónico y bacteriano. Así, el análisis demuestra que en el tiempo la abundancia de bacterias puede verse influenciado por la salinidad, lo cual podría estar relacionado a una mayor o menor influencia en el aporte del Agua Ecuatorial Subsuperficial y Agua Subantártica, situación que no fue abordada en este trabajo.

\section{VOLUMEN CELULAR Y SU RELACIÓN A LA VARIABILIDAD AMBIENTAL}

El volumen celular mostró una dependencia a un mayor número de variables, tanto individualmente como en conjunto, así la temperatura, salinidad y concentración de oxígeno disuelto presentaron índices estadísticos significativos, además, se debe de destacar que los modelos con interacción incorporan a la clorofila- $a(P<0,01)$. Esto muestra un escenario donde el volumen de los microorganismos claramente responde a los cambios del ambiente físico y a los niveles de oxígeno disuelto detectados en bahía Chipana. Anteriormente se señaló la relación entre el metabolismo (y sus requerimientos energéticos) y su respuesta en el volumen de cada célula. Lo importante de recalcar es la afinidad del bacterioplancton con el ambiente, lo cual se puede monitorear a través de cambios en el volumen celular.

\section{ESTRUCTURA DE TAMAÑo COMO PROXY DE LA COMUNIDAD DEL BACTERIOPLANCTON}

Los cambios en la estructura de tamaños pueden ser el reflejo de cómo se conforma una comunidad. En ambientes con escasos niveles de nutrientes, proliferan bacterias de pequeño tamaño que presentan un crecimiento lento en concentraciones nanomolares de sustrato (Schut et al. 1995). Sin embargo, se desconoce en profundidad la fisiología y diversidad de los microorganismos presentes en el ambiente marino, principalmente por la dificultad de aislar desde el medio 
ambiente y lograr cultivos para realizar una aproximación filogenética, fisiológica y bioquímica (Pace \& Cole 1994). El comportamiento de un microorganismo depende de sus capacidades metabólicas intrínsecas, las cuales se ven reflejadas en su actividad, tipos y vías metabólicas, que determinan el flujo de los sustratos. Lo cual se liga a la biodisponibilidad y concentraciones de estos nutrientes en el ambiente, así como con la interacción microbiana que incidirá en las tasas de flujos, y metabolización e incorporación del material particulado en el sistema.

La estructura de tamaños mostró cambios significativos, así la estructura observada en diciembre 2006 fue completamente diferente al resto de las campañas analizadas. La fracción de tamaños que une a todos los cruceros analizados, se relaciona con los estratos más pequeños de tamaños. Las partículas entre 0,4-0,8 y $0,8-1,2 \mu \mathrm{m}$ estuvieron siempre presentes, contribuyendo en promedio en un 60 y $20 \%$, respectivamente. El cambio más notable en la estructura de tamaños, se relacionó con una disminución evidente de la marca de clase entre 0,4$0,8 \mu \mathrm{m}$, que se asoció a un aumento de tamaños por sobre 1,6 $\mu \mathrm{m}$, evidenciado en el análisis SIMPER (Tabla 4).

\section{El Niño, La Niña Y EL BaCterioplanCton EN BaHIA Chipana}

Las condiciones oceanográficas sobre la plataforma continental de bahía Chipana mostraron una alta variabilidad, especialmente en la capa superficial sobre la termoclina, lo cual claramente tiene una conexión entre la alta variabilidad ambiental observada con los cambios atmosféricos y oceanográficos. De acuerdo a lo anterior, las campañas se realizaron bajo diferentes condiciones de surgencia, esto fue más evidente en las campañas estivales. Dicha condición puede ser reafirmada por la estructura termal y por la distribución del oxígeno disuelto. Durante estas campañas, además, se detectaron los mayores niveles de biomasa fitoplanctónica, sin embargo julio 2006 no respondió a dicha señal, lo que pudo deberse a la presencia de condiciones de El Niño, de carácter débil como fue descrito por Fuentes $e t$ al. (2012). Se ha descrito que en el caso de que la TSM se incrementa entre 2 y $4^{\circ} \mathrm{C}$ sobre la tendencia normal a largo plazo, se puede observar un debilitamiento de los eventos de surgencia, permitiendo incluso procesos de subducción de aguas superficiales por debilitamiento de los vientos, junto con una profundización de la termoclina dificultando la mezcla entre aguas profundas y frías, con aguas cálidas superficiales, provocando una disminución en la producción de carbono y clorofila- $a$ junto con una oxigenación de la columna de agua (Morales et al. 1999, Escribano et al 2001, Pizarro \& Montecinos 2004). Otro periodo que destaca es julio 2007, esta campaña fue realizada durante pleno desarrollo de un evento La Niña, con anomalías térmicas negativas, que en su estudio llegaron a $-2^{\circ} \mathrm{C}$ por debajo de lo normal junto con una baja productividad y clorofila- $a$ lo cual en este estudio concuerda perfectamente.

Al respecto Ducklow et al. (2001) señalan que en los ambientes donde se producen proliferaciones fitoplanctónicas estacionales (e.g., mar de Ross), serían zonas gobernadas principalmente por el material orgánico disponible para la proliferación del bacterioplancton, sin embargo dichos análisis no corroboran la apreciación anterior, es por esto que tal situación podría explicarse por una influencia indirecta del proceso de surgencia y estabilidad sobre la variabilidad bacterioplanctónica en la zona de Chipana. Pinhassi et al. (2003) sostienen que el efecto de la estabilidad sobre ciertos grupos bacterianos es más bien limitado no así con el fitoplancton. El efecto sobre estos organismos pueden afectar de manera indirecta a los grupos bacterianos, principalmente por la escasez de exudados metabólicos en el ambiente el cual es considerado clave para el funcionamiento del bacterioplancton en el océano (Azam et al. 1983), e incluso afectando al estructura comunitaria durante eventos de sucesión del fitoplancton (Pinhassi et al. 2003).

Finalmente los resultados obtenidos en este estudio señalan que la dinámica del bacterioplancton en el área de estudio, es modulada principalmente por factores ambientales físicoquímicos más que biológicos, lo cual incide sobre la abundancia, volumen, distribución, tamaño y adaptación de este (Stainier et al. 1996); estos factores reguladores del crecimiento, entre otros, son ecológica y bioquímicamente importantes para el ciclo de energía y materia en el océano (Azam \& Hodson 1977, Church et al. 2000).

\section{Agradecimientos}

Este trabajo fue financiado por el Work Package 2 del proyecto CENSOR de la Comisión de la Unión Europea. Se agradece el apoyo a esta iniciativa del Sr. Walter Sielfeld, así como también al Dr. Rosalino Fuenzalida por su dirección en el análisis de los datos físicos. Y a los evaluadores anónimos que revisaron y corrigieron el presente manuscrito.

\section{LiTERATURA CITADA}

Abarzúa M, S Basualdo \& H Urrutia. 1995. Relación entre la abundancia y biomasa del fitoplancton y bacterioplancton heterotrófico en aguas superficiales del golfo de Arauco, Chile. Investigaciones Marinas 23: 67-74.

Azam F \& RE Hodson. 1977. Size distribution and activity of marine microhetrotrophs. Limnology and Oceanography 22: 492-501. 
Azam F, T Fenchel, J Gray, L Meyer-Reil \& T Thingstad. 1983. The ecological role of water column microbes in the sea. Marine Ecology Progress Series 10: 257-263.

Bakun A. 1973. Coastal upwelling indices, West Coast of North America, 1946-71. NOAA Technical Report, NMFS-SSRF 671: 1-103.

Bode A \& E Fernández. 1992. Influence of water column stability on phytoplankton size and biomass succession patterns in the Central Cantabrian Sea (Bay of Biscay). Journal of Plankton Research 14: 885-902.

Bograd SJ, I Schroeder, N Sarkar, X Qiu, WJ Sydeman \& FB Schwing. 2009. Phenology of coastal upwelling in the California Current. Geophysical Research Letters 36: L01602, <doi:10.1029/2008GL035933>

Carpenter J. 1965. The Cheasepeake bay institute technique for the Winkler dissolves oxygen methods. Limnnology and Oceanography 10: 141-143.

Chien AC, NS Hill \& PA Levin. 2012. Cell size control in bacteria. Current Biology 22: 340-349.

Church M, D Hutchins \& H Ducklow. 2000. Limitation of bacterial growth by dissolved organic matter and iron in the Southern Ocean. Applied and Environmental Microbiology 66(2): 455-466.

Clarke KR \& RN Gorley. 2006. PRIMER v6: User Manual/ Tutorial. PRIMER-E, Plymouth.

DeLong E \& D Karl. 2005. Genomic perspectives in microbial oceanography. Nature 437(15): 336-342.

Ducklow HW. 1992. Factor regulation Bottom-up control of bacterial biomass in open ocean plankton communities. Archiv für Hydrobiologie 37: 207-217.

Ducklow HW, C Carlson, M Church, D Kirchman, D Smith \& G Steward. 2001. The seasonal development of the bacterioplankton bloom in the Ross Sea, Antarctica, 19941997. Deep-Sea Research II 48: 4199-4221.

Eissler Y, J Letelier, LA Cuevas, CE Morales \& R Escribano. 2010. The microbial community in the coastal upwelling system off Concepción, Chile, $36^{\circ} \mathrm{S}, 2002-2003$ period. Revista de Biología Marina y Oceanografía 45(1): 118.

Escribano R, V Marín \& P Hidalgo. 2001. The influence of coastal upwelling on the distribution of Calanus chilensis in the Mejillones Peninsula (northern Chile): implications for its population dynamics. Hydrobiologia 453: 143-151.

Escribano R, G Daneria, L Farías, V Gallardo, HE González, D Gutiérrez, CB Lange, CE Morales, O Pizarro, O Ulloa \& M Braun. 2004. Biological and chemical consequences of the 1997-1998 El Niño in the Chilean coastal upwelling system: a synthesis. Deep-Sea Research II 51: 2389-2411.

Escribano R \& CE Morales. 2004. Spatial and temporal scales of variability in the coastal upwelling and coastal transition zones off central-southern Chile $\left(35-40^{\circ} \mathrm{S}\right)$. Progress in Oceanography 92: 1-7.
Farías L, C Fernández, J Faúndez, M Cornejo \& ME Alcaman. 2009. Chemolithoautotrophic production mediating the cycling of the greenhouses gases $\mathrm{N}_{2} \mathrm{O}$ and $\mathrm{CH}_{4}$ in an upwelling ecosystem. Biogeosciences 6: 3053-3069.

Fuentes M, R Escribano \& LA Cuevas. 2012. Bacterial response to a weak 2006 El Niño condition in an upwelling area of the Humboldt Current System. Journal of the Marine Biological Association of the United Kingdom 92(1): 1-12.

Fry J. 1988. Determination of biomass. In: Austin B (ed). Methods in aquatic bacteriology, pp. 27-72. John Wiley and Sons, Chichester.

Galán A, V Molina, B Thamdrup, D Woebken, G Lavik, MM Kuypers \& O Ulloa. 2009. Anammox bacteria and the anaerobic oxidation of ammonium in the oxygen minimum zone off northern Chile. Deep-Sea Research II 56: 10211031.

Herrera L \& R Escribano. 2006. Factors structuring the phytoplankton community in the upwelling site off El Loa River in northern Chile. Journal of Marine Systems 61: 1338.

Landry MR. 2002. Integrating classical and microbial foodweb concepts: evolving views from the open-ocean tropical Pacific. Hydrobiologia 480: 29-39.

Legendre L \& J Le Févre. 1989. Hydrodynamical singularities as control of recycled versus export production in oceans. In: Berger WH, VS Smetacek \& G Wefer (eds). Productivity of the ocean: Present and past, pp. 49-63, John Wiley and Sons, New York.

Loferer-Krößbacher M, J Klima \& R Psenner. 1998. Determination of bacterial cell dry mass by Transmission Electron Microscopy and Densitometric Image Analysis. Applied and Environmental Microbiology 64(2): 688-694.

Malone TC. 1980. Algal size. In: Morris I (ed). The physiological ecology of phytoplankton, pp. 433-464. Blackwell Scientific Publications, Oxford.

Massana R, J Gasol, P Bjørnsen, N Blackburn, A Hagström, S Hietanen, BH Hygum, J Kuparinen \& C Pedrós-Alió. 1997. Measurement of bacterial size via image analysis of epifluorescence preparations: description of an inexpensive system and solutions to some of the most common problems. Scientia Marina 61(3): 397-407.

Molina V \& L Farías. 2009. Aerobic NH4+ oxidation in the oxycline and oxygen minimum zone of the eastern tropical South Pacific off northern Chile $\left(\sim 20^{\circ} \mathrm{S}\right)$. Deep Sea Research, Part II 56: 1009-1018.

Morales C, S Hormazábal \& JL Blanco. 1999. Interannual variability in the mesoscales distribution of the depth of the upper boundary of the oxygen minimum layer off northern Chile (18-24S): Implications for the pelagic system and biogeochemical cycling. Journal of Marine Research 57: 909932. 
Mukhanov VS, OG Naidanova, OA Lopukhina \& RB Kemp. 2007. Cell-, biovolume- and biosurface-specific energy fluxes through marine picoplankton as a function of the assemblage size structure. Thermochimica Acta 458:2333 .

Pace ML \& JJ Cole. 1994. Comparative and experimental approaches to top-down and bottom-up regulation of bacteria. Microbial Ecology 28: 181-193.

Palma W, R Escribano \& SA Rosales. 2006. Modeling study of seasonal and inter-annual variability of circulation in the coastal upwelling site of the El Loa River off northern Chile. Estuarine, Coastal and Shelf Science 67: 93-107.

Pantoja S. 2006. Biogeochemistry of the OMZ off Chile. Gayana 70(1): 62-67.

Parsons T, Y Maita \& C Lalli. 1984. A manual of chemical and biological methods for seawater analysis, $330 \mathrm{pp}$. Pergamon Press, Oxford.

Pernthaler J, I Sattler, K Simek, A Schwarzenbacher \& R Psenner. 1996. Top-down effects on the size-biomass distribution of a freshwater bacterioplankton community. Aquatic Microbial Ecology 10:255-263.

Pinhassi J, A Winding, S Binnerup, UL Zweifel, B Riemann \& A Hagstrom. 2003. Spatial variability in bacterioplankton community composition at the Skagerrak-Kattegat front. Marine Ecology Progress Series 255: 1-13.

Pizarro O \& A Montecinos. 2004. El Niño y la Oscilación del Sur. En: Werlinger C (ed). Biología marina y oceanografía: Conceptos y procesos, pp. 195-222. Consejo Nacional del Libro y la Lectura-Universidad de Concepción, Trama Impresores, Concepción.

Pulido-Villenas E \& I Reche. 2003. Exploring bacterioplankton growth and protein synthesis to determine conversion factors across a gradient of dissolved organic matter. Microbial Ecology 46: 33-42.

Rodríguez J, J Tintoré, JT Allen, JM Blanco, D Gomis, A Reul, J Ruiz, V Rodríguez, F Echevarría \& F JiménezGómez. 2001. Mesoscale vertical motion and the size structure of phytoplankton in the ocean. Nature 410: 360363.
Semina HJ. 1968. Water movement and the size of phytoplankton cells. Sarsia 34: 267-272.

Semina HJ. 1972. The size of phytoplankton cells in the Pacific Ocean. International Revue Gesampten Hidrobiologie 57: 177-205.

Schut F, M Jansen, TMP Gomes, JC Gottschal, W Harder \& RA Prins. 1995. Substrate uptake and utilization by a marine ultramicrobacterium. Microbiology 141:351-361.

Stainier R, JL Ingraham, ML Wheelis \& PR Painter. 1996. The microbial world, 22 pp. Prentice-Hall, Englewood Cliffs.

Stevens H \& O Ulloa. 2008. Bacterial diversity in oxygen minimum zone of the eastern tropical South Pacific. Environmental Microbiology 10(5): 1244-1259.

Strub PT, JM Mesias, V Montecino, J Rutllant \& S Salinas. 1998. Coastal ocean circulation off western South America. In: Robinson AR \& KH Brink (eds). The Sea 11: 273-314. John Wiley and Sons, New York.

Troncoso VA, G Daneri, LA Cuevas, B Jacob \& P Montero. 2003. Bacterial carbon flow in the Humboldt Current System off Chile. Marine Ecology Progress Series 250: 1-12.

Vargas CA \& HE González. 2004. Plankton community structure and carbon cycling in a coastal upwelling system. II. Microheterotrophic pathway. Aquatic Microbial Ecology 34: $165-180$.

Vargas CA, R Martínez, LA Cuevas, MA Pavez, C Cartes, HE González, R Escribano \& G Daneri. 2007. The relative importance of microbial and classical food webs in a highly productive coastal upwelling area. Limnology and Oceanography 52: 1495-1510.

Wood SM. 2006. Generalized additive models: An Introduction with R, 392 pp. Chapman and Hall, London. 